\title{
洋县水库降等报废情况调查报告
}

\author{
朱晓红 \\ 洋县水利技术服务中心 \\ DOI:10.32629/hwr.v3i6.2190
}

[摘 要] 水库安全运行对于当地农业发展以及农民正常生产生活非常重要, 因此为了加强水库安全管理, 根据水利部的有 关规定, 运行期间的大坝, 每隔6-10年组织一次安全鉴定, 每隔5年对登记事项普遍普查一次, 运行中遭受特大洪水、工程 发生重大事故或影响安全的异常现象后, 应组织专门的安全鉴定。所以为了有效确认我县的水库运行状况, 经对全县小型水 库安全状况进行调查,对失去水库功能的小型水库及时申请降等报废,提出几点建议。

[关键词] 小型水库; 降等报废; 调查及建议

\section{1 水库基本情况}

我县共有水库 86 座, 其中: 中型水库 3 座, 小 (一) 型水库 9 座, 其余 74 座为小 (二) 型水库。总库容为 13445 万 $\mathrm{m}^{3}$, 有效灌 溉面积 24.5 万亩。党河、沙河、引酉局、峡口堰、胥惠渠马 管站5个国营灌区管理单位负责对党河、卡房、沙河 3 座中型 水库以及都家沟、高家河、双龙寺等 21 小型水库进行管理, 以上水库管理单位为全民事业单位, 按规范编制运行管理及 度汛预案, 报市、县审批执行, 服从上级调度指令。管理上做 到各库责任落实到人, 24 小时制守, 专人专管, 定期进行工程 观测, 收集资料, 及时反馈相关信息。其余65座小型水库实行 镇村两级混合管理的体制, 分别由镇政府或受益村委会管理。

长期以来, 水库为改善我县农业生产条件, 保障粮食丰 收、农民致富做出了巨大的贡献, 特别是中型水库, 库容量及 灌溉面积分别占我县水库总设计库容量及灌溉面积的 $59 \%$ 和 $67 \%$, 在我县防洪抗旱中发挥着举足轻重的作用, 对我县农业 发展起到了积极的保障作用。

\section{2 病险水库除险加固情况}

截止目前洋县列入全国震损水库及病险水库除险加固 工程项目的水库共有 60 座, 其中 2008 年5. 12 地震后震损水库 除险加固 10 座; 病险水库除险加固的共有 50 座。已完工并通 过竣工验收的震损加固水库 10 座, 已完工并通过竣工验收的 病险水库 33 座, 在建的病险水库 17 座。病险水库得到治理, 占全县水库总数的 $70 \%$, 水库大坝、溢洪道、放水设施安全隐 患得到彻底根除, 防洪标准达标, 水库安全状况得到极大改 善。剩余26座一般性小型水库, 对失去水库功能的5座小型水 库及时申请报废, 其余加强日常管理, 及时维修养护, 确保运 行安全。

\section{3 水库安全状况}

我县水库大多数修建于上世纪50-70年代, 水库基础设 施较为简陃, 配套设施不完善, 长期以来, 由于各级政府缺乏 资金投入, 水库运行管理和维修养护经费严重不足, 我县大 部分水库及其配套工程普遍存在年久失修、水库大坝潜在安 全隐患多、水库淤积严重、渠道毁坏渗漏等问题, 制约了水 库效益的有效发挥。各水库蓄水量逐年减少, 保障农业正常
灌溉用水压力逐年增大, 效益逐年衰减。由于镇、村管理的 水库管理体制不顺、机制不活, 大部分无经费、收入少、小 (二) 型水库没有配备专职管水人员, 日常管理主要靠村组干部兼 职, 部分水库依靠养鱼承包户进行管理, 管理不到位, 安全隐 患较多。群众用水灌溉与承包方蓄水养殖存在一定的矛盾, 损害群众的合法权益。承包方有意蓄水养鱼而减少泄水量, 水满溢库, 危及群众生命财产安全。镇村管理水库通过行政 命令基本能维持水库正常运行。

为保证安全管理落到实处, 县水利局从 2008 年开始, 成 立了县防汛技术组, 主要对汛期水库突发险情应急处理提供 技术保障和决策依据。从 5 月 10月开展 $3 \sim 5$ 次防汛安全大 检查, 重点对水库三大件大坝、溢洪道、泄水建筑物完好情 况、管理人员在岗情况、汛限水位执行情况、溢洪道拦网设 障情况进行检查, 检查情况由被检查单位负责人签字盖章后 报县防汛办汇总, 对存在问题进行全县通报, 限期整改到位, 确保了水库运行安全。同时, 随着全县病险水库除险加固工 程的实施, 60 座病险水库得到治理, 占全县水库总数的 $70 \%$, 水库大坝、溢洪道、放水设施安全隐患得到彻底根除, 防洪 标准达标, 水库安全状况得到极大改善。继续加强对一般性 小型水库的日常管理, 对失去水库功能的小型水库及时申请 降等报废, 使水库逐步走上良性发展的轨道。

\section{4 小型水库降等报废调查成果}

经对全县小型水库认真摸排, 因水毁、淤积严重需要报 废的水库共 5 座, 均为小 (二) 型水库, 分别是戚氏镇力劲坡、 石羊、四合、石头河水库, 谢村镇老庄水库。

\section{1 力劲坡水库}

力劲坡水库位于汉江左岸一级支流亘溪河山口处的戚 氏镇山后村, 距洋县城约 $8 \mathrm{~km}, 1976$ 年10月动工修建, 1978年5 月建成蓄水, 水库枢纽由浆砌石拱坝、开敞式挑流溢洪道、 泄水设施等组成。坝址以上控制流域面积 $13.8 \mathrm{~km}^{2}$, 坝高 $23 \mathrm{~m}$, 坝长 $70.5 \mathrm{~m}$, 坝顶高程 $575 \mathrm{~m}$, 校核洪水位 $574 \mathrm{~m}$, 设计洪水位 $573 \mathrm{~m}$, 正常蓄水位 $572.5 \mathrm{~m}$, 死水位 $560 \mathrm{~m}$ 。洪水标准: 30 年一遇 设计, 300 年一遇校核。总库容 52 万 $\mathrm{m}^{3}$, 兴利库容 48 万 $\mathrm{m}^{3}$, 死库 容 2 万 $\mathrm{m}^{3}$ 。设计灌溉面积 2000 亩, 实灌 200 亩, 采用原站抽水解 
决灌溉用水, 扬程 $90 \mathrm{~m}$ 。该库建成后由戚氏镇上赵村负责管 理。由于该流域属秦岭南坡丘陵区, 干旱缺水, 植被稀少, 开 荒、采矿等人为破坏造成水土流失严重, 水库淤积逐年增加。 据 1982 年测定库容淤积量 39.6 万 $\mathrm{m}^{3}$, 占总库容的 $76 \%$, 年淤积 量 5.65 万 $\mathrm{m}^{3}$ 。该库已于 1992 年基本淤平, 失去蓄水功能。上 赵村抽水站也于1996年峡口堰灌区正式通水后报废, 灌溉面 积计入峡口堰灌区, 由峡口堰自流引水解决灌溉用水, 确保 当地群众粮食丰收、安居乐业。目前该库实际已经报废, 不 再发挥防洪灌溉效益。

\section{2 石羊水库}

石羊水库位于戚氏镇石羊村, 属汉江左岸二级支流四合 沟流域, 距洋县城 $12 \mathrm{~km}, 1976$ 年12月动工修建, 1977年2月建成 蓄水, 水库枢纽由均质土坝、开敞式溢洪道、放水设施等组成。 坝址以上控制流域面积 $4.7 \mathrm{~km}^{2}$, 坝高 $11.5 \mathrm{~m}$, 坝长 $81 \mathrm{~m}$, 坝顶高 程 $499.7 \mathrm{~m}$, 校核洪水位 $498.5 \mathrm{~m}$, 设计洪水位 $498 \mathrm{~m}$, 正常蓄水位 $497 \mathrm{~m}$, 死水位 $490.5 \mathrm{~m}$ 。洪水标准: 30 年一遇设计, 300年一遇校 核。总库容 11.1 万 $\mathrm{m}^{3}$, 兴利库容 8.3 万 $\mathrm{m}^{3}$, 死库容 1.3 万 $\mathrm{m}^{3}$ 。设计 灌溉面积795亩, 实灌120亩, 采用洜站抽水解决灌溉用水, 扬 程 $55 \mathrm{~m}$ 。该库建成后由戚氏镇石羊村负责管理。由于该流域属 秦岭南坡丘陵区, 干旱缺水, 植被稀少, 开荒、种地等人为破坏 造成水土流失严重, 水库淤积逐年增加。据2002年测定库容淤 积量 2.8 万 $\mathrm{m}^{3}$, 占总库容的 $25 \%$ 。由于淤积严重, 库尾逐年抬高, 加之人口增加, 群众沿沟道修建房屋, 浸占、束窄河道, 造成 水流不畅, 一遇汛期洪水上涨, 库水倒灌, 淹没农田、房屋, 群众财产损失巨大, 安全无保证。考虑到群众生命财产安 全, 2011年经村民代表大会一致通过, 同意对石羊水库予以 报废, 不再蓄水。石羊水库以上水田依靠上游邓家庙水库自 流引水解决灌溉用水, 下游及坡地全部改种旱作物, 临时用 水采用微型水洜抽水解决。目前该库实际已经报废, 不再发 挥防洪灌溉效益。

\section{3 四合水库}

四合水库位于戚氏镇魏家庙村, 属汉江左岸二级支流四 合沟流域, 距洋县城 $11 \mathrm{~km}, 1965$ 年 12 月动工修建, 1967年4月 建成蓄水, 水库枢纽由均质土坝、开敞式溢洪道、放水设施 等组成。坝址以上控制流域面积 $9.6 \mathrm{~km}^{2}$, 坝高 $15 \mathrm{~m}$, 坝长 $80 \mathrm{~m}$, 坝顶高程 $519.3 \mathrm{~m}$, 校核洪水位 $518 \mathrm{~m}$, 设计洪水位 $517 \mathrm{~m}$, 正常蓄 水位 $516.4 \mathrm{~m}$, 死水位 $508 \mathrm{~m}$ 。洪水标准：30年一遇设计, 300年 一遇校核。总库容 30 万 $\mathrm{m}^{3}$, 兴利库容 27 万 $\mathrm{m}^{3}$, 死库容 1.1 万 $\mathrm{m}^{3}$ 。 设计灌溉面积405亩, 实灌120亩。该库建成后由戚氏镇魏家 庙村负责管理。由于该流域属秦岭南坡丘陵区, 干旱缺水, 植被稀少, 开荒、种地等人为破坏造成水土流失严重, 水库淤 积逐年增加。据 2002 年测定库容淤积量 8.7 万 $\mathrm{m}^{3}$, 占总库容的 $29 \%$ 。由于淤积严重, 库尾逐年抬高, 一遇汛期洪水上涨, 库水 倒灌, 淹没上游农田, 群众财产损失巨大, 安全无保证。水库 下游农田已纳入洋县党河灌区溢惠渠灌溉范围, 不再承担灌 溉任务, 实际只用于私人承包养鱼。目前该库实际已经报废, 不再发挥防洪、灌溉效益。

\section{4石头河水库}

石头河水库位于戚氏镇七眼泉村, 属汉江左岸二级支流 石头河流域, 距洋县城 $8 \mathrm{~km}, 1964$ 年8月动工修建, 1965年2月建 成蓄水, 水库枢纽由均质土坝、开敞式溢洪道、放水设施等组 成。坝址以上控制流域面积 $0.5 \mathrm{~km}^{2}$, 坝高 $8.3 \mathrm{~m}$, 坝长 $130 \mathrm{~m}$, 坝顶 高程 $502.5 \mathrm{~m}$, 校核洪水位 $501.5 \mathrm{~m}$, 设计洪水位 $500.5 \mathrm{~m}$, 正常蓄 水位 $500 \mathrm{~m}$, 死水位 $496 \mathrm{~m}$ 。洪水标准：30年一遇设计, 300年一 遇校核。总库容 10.1 万 $\mathrm{m}^{3}$, 兴利库容 $9.5 \mathrm{~m}^{3}$, 死库容 0.1 万 $\mathrm{m}^{3}$ 。 设计灌溉面积 600 亩, 实灌 120 亩。该库建成后由戚氏镇七眼 泉村负责管理。由于该流域属秦岭南坡丘陵区, 干旱缺水, 植被稀少, 开荒、采矿等人为破坏造成水土流失严重, 水库淤 积逐年增加。据2002年测定库容淤积量 3.6 万 $\mathrm{m}^{3}$, 占总库容的 $36 \%$ 。由于淤积严重, 库尾逐年抬高, 一遇汛期洪水上涨, 库水 倒灌, 淹没上游农田, 群众财产损失巨大, 安全无保证。水库 下游农田已纳入洋县党河灌区溢惠渠灌溉范围, 不再承担灌 溉任务, 实际只用于私人承包养鱼。该库位于七眼泉村后, 坝下游为人口密集居住区和县水泥厂, 直线距离仅 10 米, 是 真正的头顶 “悬河”, 一旦溃坝群众生命财产安全损失巨大。 由于该库不再承担灌溉任务, 考虑到群众生命财产安 全, 2011年经村民代表大会一致通过, 同意对石头河水库予 以弃旱报废, 不再蓄水。目前该库实际已经报废, 不再发挥防 洪、灌溉效益。

\section{5 老庄水库}

老庄水库位于谢村镇老庄村, 属汉江左岸二级支流雷草 沟流域, 距洋县城 $14 \mathrm{~km}, 1975$ 年 12 月动工修建, 1976年5月建 成蓄水, 水库枢纽由均质土坝、开敞式溢洪道、放水设施等 组成。坝址以上控制流域面积 $1 \mathrm{~km}^{2}$, 坝高 $15 \mathrm{~m}$, 坝长 $175 \mathrm{~m}$, 坝顶 高程 $599.5 \mathrm{~m}$, 校核洪水位 $598.5 \mathrm{~m}$, 设计洪水位 $598.3 \mathrm{~m}$, 正常蓄 水位 $598 \mathrm{~m}$, 死水位 $585 \mathrm{~m}$ 。洪水标准: 20 年一遇设计, 200 年一遇 校核。总库容 22.6 万 $\mathrm{m}^{3}$, 兴利库容 19.1 万 $\mathrm{m}^{3}$, 死库容 2.5 万 $\mathrm{m}^{3}$ 。 设计灌溉面积 200 亩, 实灌120亩。该库建成后由谢村镇老庄村 负责管理。由于该流域属秦岭南坡丘陵区, 干旱缺水, 植被稀 少, 开荒、采矿等人为破坏造成水土流失严重, 水库淤积逐年 增加。据 2002 年测定库容淤积量 7.5 万 $\mathrm{m}^{3}$, 占总库容的 $33 \%$ 。 由于淤积严重, 库尾逐年抬高, 一遇汛期洪水上涨, 库水倒灌, 淹没上游农田, 群众财产损失巨大, 安全无保证。该库流域面 积小, 径流水量少。不能满足灌溉需求, 灌溉面积急剧萎缩, 至2003年水库已经弃旱, 不再蓄水。为弥补水库承包养鱼损 失, 村委会同意养鱼户在库内栽树。目前该库实际已经报废, 不再发挥防洪、灌溉效益。

\section{5 存在问题及建议}

5. 1 存在问题

由于存在问题需降等报废的水库基本是由镇村管理的, 大部分无经费、收入少、无专人管理, 通过行政命令勉强能 维持水库正常运行。但要按照《水库降等报废管理办法》制 定降等报废方案, 开展相关工作还有一定困难：一是镇村不 具备相关的技术能力, 开展本项工作没有经费支持; 二是相 


\section{$10 \mathrm{kV}$ 高压柜的故障及防范措施}

靳文德

青海铜业有限责任公司

DOI:10.32629/hwr.v3i6.2253

[摘 要] 随着我国电力行业的快速发展和深入改革, $10 \mathrm{kV}$ 高压开关柜的使用变得越来越普及。10kV的高压柜不仅可以很好的 维持电力系统稳定工作, 而且在发生故障时能够断开连接设备,方便对其采取有效的维修措施,不易产生故障。对 $10 \mathrm{kV}$ 的高压柜 的故障诊断并且采取相应的措施可以更好地发挥它全面的安全作用。本文就我厂 $10 \mathrm{kV}$ 高压柜的故障及防范措施进行论述 分析。

[关键词] $10 \mathrm{kV}$ 高压柜; 故障; 防范措施

\section{$110 k V$ 高压柜种类及特点}

1. 1 高压柜种类

近年来, $10 \mathrm{kV}$ 高压柜的使用越来越受到人们的关注。由于 当前使用的 $10 \mathrm{kV}$ 高压柜种类多种多样, 作为重要部件的开关 柜之间有着明显的区别, 因此故障发生的概率也大为不同。总 体来说, 开关柜主要箱式开关柜、固定式开关柜、手车落地式 开关柜、HXGN负荷开关柜和手车中置式开关柜五种类型。

\section{2 高压柜特点}

固定式开关柜的优点是体积大, 柜内空间大, 不仅可以 随意摆放元器件而且可以任意改造。但其由于封闭性和防护 性较差, 发生事故的概率较高, 目前基本上已被淘汰。箱式开 关柜拥有全封闭的外壳, 可有效地节省空间, 同时, 由于体积 小, 散热性能差, 不适用于较大负荷的供电系统。相对而 言, HXGN负荷开关柜因其防护等级较高、维护相对简单, 已经 被广泛应用于新建用电房中。手车落地式开关柜对箱底的强 度要求高, 目前, 是市场上倾向于采用进口技术生产的产品。 手车中置式开关柜和其他同类产品相比有着明显优势, 因此, 是目前在 $10 \mathrm{kV}$ 高压柜中应用最广、最受欢迎的产品。

\section{2 造成 $10 k V$ 高压柜发生故障的因素}

2.1绝缘因素

绝缘能力是判断电力设备好坏的一项重要指标, 也是影
响高压开关柜正常工作的重要因素。在进行电力维修时, 使 用的电力产品质量参差不齐, 很容易在维修过程中给电力设 备带来损坏, 降低其绝缘能力。另外, 维修人员的维修程序不 规范, 也极易给供电设备的绝缘能力造成损坏。在开关柜平 时的使用过程中, 电力系统高负载的运行往往会产生一定的 热量, 久而久之会就使开关柜绝缘层性能逐步降低。

\section{2 安装、检修维护隐患}

在对高压开关柜进行安装或者维修的过程中, 由于操作 人员水平的限制, 有时不但不能及时发现设备故障, 还有可 能增加设备的不安全因素, 有可能会出现电缆绝缘层损坏。 比如, 在对母线和各个出线安装或检修时, 工作量很大, 这就 很容易造成个别螺栓固定不牢固, 在实际运行中连接处就会 产生大量的热量, 造成母线和各出线不得不进行停电维修。 在高压开关柜发生的事故中, 因为电缆的制作工艺不良造成 柜内电路短路的情况占大多数。另外, 在对高压开关柜进行 操作时, 没有将电缆头内的气体全部排出, 不经意的刀割也 会将电缆线的绝缘层损坏。

\section{3质量原因}

高压柜是否出现故障和电力设备以及电力材料质量的 好坏有着密切的关系。在电力工程建设或者改造过程中, 用 到的各种设备和材料, 其质量的好坏对整个系统的发电、供
关审批程序复杂, 镇村积极性不高; 三是后续承包养鱼赔偿 问题比较普遍, 处理很复杂。

\section{2 建议}

一是对水库降等报废工作应予以适当补助, 根据实际工作量 和支出, 通过验收后采用报账制由财政给予补助。二是简化 小 (二) 型水库降等报废审批程序, 由管理单位会同镇村召开 群众大会, 征得群众同意, 在妥善处理好灌溉、养鱼、防洪等 关系的情况下, 可自行开展降等报废工作, 再向县级水利部 门备案, 以稳步推进水库降等报废工作顺利开展。三是将小 型水库一般病害治理纳入财政预算, 完善防洪设施, 提高应 对突发事件的能力。四是加大对小型水库维修养护资金的投 入和支持力度, 建议每库每年由中央财政安排 $2 \sim 3$ 万元资金
予以补助, 配齐管理人员, 充分发挥管理职责, 确保水库安 全。五是为充分发挥水库的社会效益, 保证群众抵抗水旱灾 害的需要, 维护好群众的合法权益, 建议政府对已发包的水 库养鱼经营权进行清理, 合理提高承包费, 增加水库收入, 不 合理的坚决收回承包权。

\section{[参考文献]}

[1]荆茂涛,杨正华,蒋金平.全国水库降等与报废情况调 查分析[J].中国水利,2018,(20):12-14+45.

[2]高杰.浅谈水库降等与报废 [J]. 中国水能及电气 化,2018,(11):54-56.

[3]成荣亮,杨正华.小型水库降等与报废成本效益评价 模型研究[J].人民长江,2016,47(24):101-105. 